\title{
Improving EFL classroom interaction by understanding students' learning styles
}

\author{
Bui Phu Hung \\ Department of Foreign Languages, University of Finance and Marketing, Ho Chi Minh City, Vietnam
}

\section{Email address:}

buiphuhung@yahoo.com

\section{To cite this article:}

Bui Phu Hung. Improving EFL Classroom Interaction by Understanding Students' Learning Styles. International Journal of Language and Linguistics. Vol. 2, No. 6, 2014, pp. 379-386. doi: 10.11648/j.ijl1.20140206.17

\begin{abstract}
Multiple Intelligences (Gardner, 1993) postulates a standpoint that people may prefer to learn in different ways as a result of their predominance of different lobes. In particular, some deal well with sounds, but others appear to have a good sense of syntactic areas. It is important for the teacher to understand students' learning styles in order to help them improve their language competencies to the most. With a sufficient understanding of students' learning style preferences, teachers can use appropriate strategies and activities in language classes. The research study has proved the matching of teaching and learning styles and the classroom EFL interaction are positively correlated.
\end{abstract}

Keyword: Learning Styles, Interaction, Motivation

\section{Introduction}

\subsection{Background}

Multiple Intelligences is still a new area in Vietnam; teachers just apply the teaching styles they prefer. Some students appear to be apathetic in classroom, but others prefer the teaching style applied. The mismatch of teaching style and learning style is partly responsible for students' passiveness.

\subsection{Significance of the Study}

The proposed research is intended to contribute an insight into Vietnamese learning styles because different cultures may appear to have different learning styles (Worthley, 1987) as the perspective has never been discovered in Vietnam. After having explored students' learning styles, researchers will simply propose teaching strategies through classroom observations on students' interaction. This research is designed to experiment proposed teaching strategies with repeated adjustments of teaching strategies according to students' reaction to bridge the gap between teachers' and learners' perceptions. The findings will probably be used to develop learners' classroom performance at Hong Duc University and can be applied by other Vietnamese EFL teachers.

\section{Literature Review}

\subsection{Learning Styles}

\subsubsection{Definition}

A learning style is "the complex manner in which, and conditions under which, learners most efficiently and most effectively perceive, process, store, and recall what they are attempting to learn" (James and Gardner, 1995: 20).

\subsection{The Basis of Learning Styles (Kolb, 1984)}

Neurologists have concluded that a learning style preference takes place as a result of the dominance of a part of human brain; there are six varied learning styles accordingly (Fig. 1).

Visual learning style is managed by occipital lobes, at the rearmost portion of the brain, and parietal lobes, positioned above the occipital lobes and behind the frontal lobes.

Auditory learning style is one in which temporal lobes, with primary auditory cortex, handle aural content, processing of semantics in speech and music.

Another major style is defined as kinesthetic learning style, in which cerebellum and the motor cortex, at the back of the frontal lobe, deal with much of human physical movement, recognizing future consequences resulting from current actions.

Tactile learning style is a one that learners prefer to work 
with hands, which is regulated by the motor cortex at the rear of the frontal lobe. The basic distinction between kinesthetic and tactile styles is tactile learners are those who get their hands involved, while kinesthetic learners use the whole body while learning.

Additionally, the frontal and temporal lobes control much of our social activities, which is responsible for a style labeled group learning style. The limbic system, not shown apart from the hippocampus, also influences this style.

Individual or Solitary Learning Style is one in which the frontal and parietal lobes, and the limbic system, are also active.

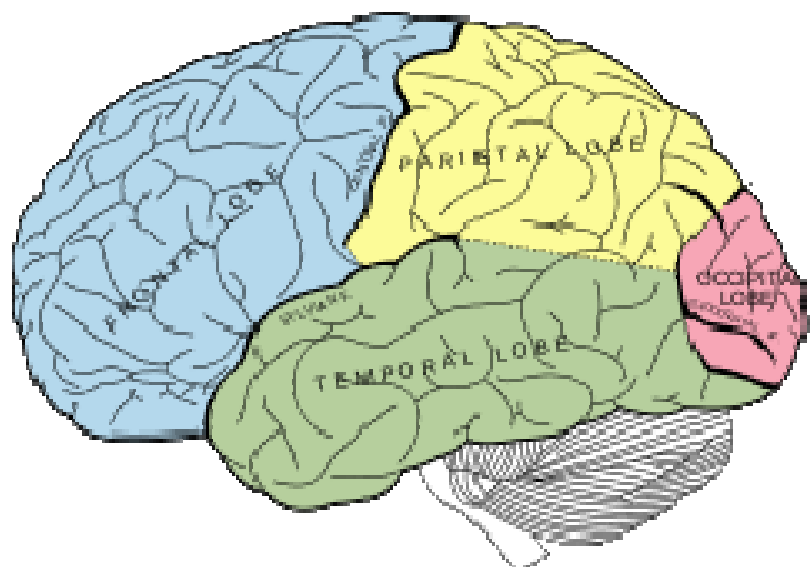

Figure 1. Human brain

\subsection{The Brain and Language}

Gardner (1993) has hypothesized the theory of Multiple Intelligences by stating that many people, with and without normal development, exhibit good language competencies due to their phonetic, syntactic, and semantic abilities.

By and large, the left hemisphere of the brain is responsible for language development. Those who rely on analytic mechanisms of the right hemisphere make sense of sentences based on the principal lexical items. Specifically, they explore the meanings of sentences based on the principal lexical items, while proving unable to utilize cues of syntax which is proved to be the responsibility of the left hemisphere. In summary, both left and right hemidecorticates are able to understand sentences whose meaning can be inferred simply from a knowledge of the meaning of substantives.

\subsection{Dimensions of Learning Styles}

The learning style may be measured in terms the answers to the following four questions:

a. What type of information does the student preferentially perceive?

b. Through which modality is sensory information most effectively perceived?

c. How does the student prefer to process information?

d. How does the student progress toward understanding?

\subsection{Explanation of Learning Style Preferences}

Reid (1984) explains 6 major learning styles, namely visual, auditory, kinesthetic, tactile, group, and individual. Additionally, he also adds 2 unusual learning styles called minor and negligible. The hypotheses discussed below are based on Kolb's theories (1984), Reid's perspectives (1984), and Honey and Mumford's research findings (1982).

\subsubsection{Visual Major Learning Style Preference}

A student with the visual style usually prefers learning visually to absorb information and converse with others by using eyes to sense things.

If a teacher identifies this learning style among students, he or she should use visual aids to assist teaching.

\subsubsection{Auditory Major Learning Style Preference}

Auditory learners exhibit keenness on being sounds, singing and playing a musical instrument.

When teachers recognize students with this learning style, they may use sounds to help students study effectively.

\subsubsection{Kinesthetic Major Learning Style Preference}

Kinesthetic learners learn best when they move, including getting involved in projects, discovery, role-playing, simulations and games.

Teachers are advised to let kinesthetic students take part in physical activities actively. For instance, they can be required to assemble an engine to understand its components, rather than read or look at diagrams.

\subsubsection{Tactile Major Learning Style Preference}

Tactile learners are those who prefer to do hands-on experiences to acquire the target lesson by handling and building models, and touching and working with materials.

Teachers had better create activities sot that tactile learners can feel things with hands. Role-playing and simulating may do some help.

\subsubsection{Group Major Learning Style Preference}

Students with this style seem to socialize well with other people and are also sensitive to motivation, feelings or moods.

Identifying social learners, teachers should assign pair or group work because students can try to obtain the task objectives through comments from others.

\subsubsection{Individual Major Learning Style Preference}

These students are in favor of independent learning. They are able to integrate their thoughts and feelings successfully when they are on their own.

To assist their academic development, students can be required to spend a sufficient amount of time setting their own goals and creating their interest in an assigned topic.

\subsubsection{Minor Learning Styles}

In most cases, accomplished scholars have a mix of learning styles, which makes them be flexible or easily adapt to different subject requirements without effort. 


\subsubsection{Negligible Learning Styles}

A negligible style means the responder kinds it hard to learn that way. An approach may be for the learner to turn to a more dominant style or attempt skills to improve it.

\subsection{The Teacher's Need to Understand Students' Learning Styles}

\subsubsection{Potential Unwanted Side Effects from the Applications of Learning Styles}

People may believe it is significant to match the teaching and learning style. However, learning styles are likely subject to change. A point is a learning style preference may take time to change. For a short run, to be practical, the match of teaching and learning style is really essential. Additionally, those who discover their specific style does not fit the teachers' style may give up.

Most efforts to match students and teachers have had comparatively little impacts on academic results because everyone is capable of going beyond the particular learning style at a time.

\subsubsection{Teaching Strategies Rather Than Learning Strategies Should be Focused on to Enhance Students' Interaction}

Teachers should encourage students by using the teaching style compatible with students' one before asking them to modify their behavior (Fig. 2).

\section{Teaching styles and classroom interaction}

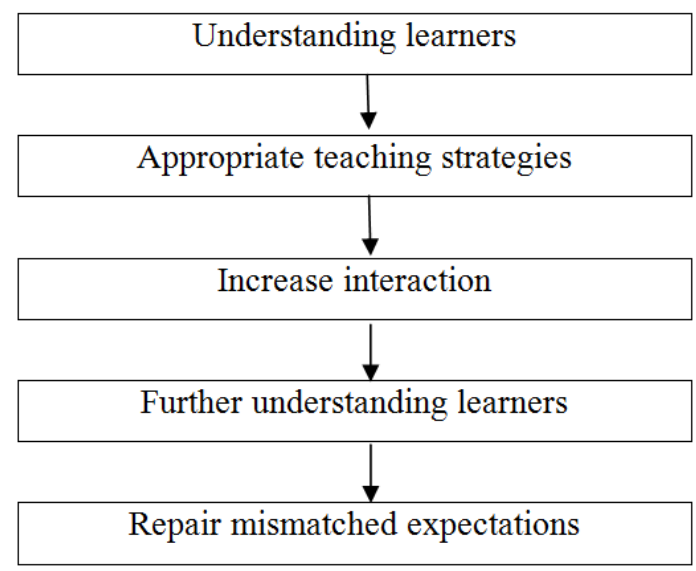

Figure 2. Language classroom interaction

Language classroom interaction proves crucial in that students can achieve their communication skills and language from the teacher and peers (Harker, 1988: 223). In addition, expectations cannot be reached with inadequate negotiations (Good \& Brophy, 1987: 296-303).

\section{Research Methods}

\subsection{Subjects}

\subsubsection{Student Samples}

150 students of 6 state-financed EFL classes of intermediate level at International Education Center of Hong
Duc University in Thanh Hoa Province were involved in the research study for the validity and reliability of the research. The number of students in each class did not exceed 25 (Kelen, 2000), all of whom were aged from 18 - 40 and used Vietnamese as their native language. The classes TU1, TU2, TU3, and TU4 all consisted of civil servants, aged 27 to 40 and they were required to study English by the state. The students from classes K6A and K6B were voluntary students, whose age range was between 18 and 30 . That means, they registered for the course themselves as they wanted to study English as a prerequisite to study overseas.

\subsubsection{Teacher Samples}

9 teachers, including 4 female and 5 male full-time teachers aged 24-55, who had been teaching at International Education Center, participated in the research. 2 American teachers and 1 Swedish teacher had a bachelor's degree, 1 Australian teacher with a master's degree, 1 Australian teacher with a $\mathrm{PhD}, 1$ Vietnamese teacher with a $\mathrm{BA}$ of TESOL, 1 Vietnamese teacher with a MA of TESOL, and 1 Vietnamese teacher as a doctoral candidate of TESOL. All the teachers who were not native to Vietnam did not major in TESOL, but they had an internationally-accredited certificate of TESOL. The teachers' understanding of their students' learning styles were explored in the survey, but their intuitive understanding of this proficiency group's background and behavior deserved appreciating and sharing for data collection at the first phase of the study and classroom at its later phases.

\subsection{Research Conditions}

\subsubsection{Conditions for Psychoanalysis of Learning Styles}

Learners often adapt their styles to the learning situation and so learners of one style may display characteristics of another style at certain times (Willing, 1987). The exploration of factors that cause the transition from past to present learning styles, to some extent, helps realize the effectiveness of the teaching strategies students have received.

\subsubsection{Conditions for Minimizing Misleading Factors}

Firstly, interaction reluctance results from linguistic incompetence as learners struggle in dealing with English sounds and understanding of grammar patterns (Burns \& Joyce, 1997: 134-135). Thus students' interaction shyness because of low proficiency level can be misunderstood as a mismatch between learning and teaching styles (Krashen, 1982).

Secondly, those who are intrinsically motivated may get involved more in interaction rather than the students who are forced to study, which may be misinterpreted as a certain modality of learning styles and may lead to a wrong remedy.

\subsubsection{Conditions for Longitudinal Study}

Since the study is the repeated intervention in a sample, the consistency of the participants is required. Administrative policy at the center is that no student is allowed to drop out of the project. Otherwise, the subject will received a 
punishment from his or her organization. This helps sustain the consistency of the sample.

\subsection{Applied Instruments: Questionnaires, Observation Checklists and Recorders}

\subsubsection{Procedure}

The study consists of 5 stages.

Stage 1: Preparation (Surveying to explore learning styles and motivation levels among students at IEC and student placement)

Two questionnaire surveys, in translated forms, were intended to explore the distribution of learning styles and motivation among the students of all the 6 classes. The questionnaire (Reid, 1984) comprises close questions to recognize the students' learning styles. It has two parts. Part I asks respondents for some basic biographical data; Part II, with 30 questions, seeks to identify respondents' learning styles (Table 1).

Table 1. Questions for each learning styles

\begin{tabular}{ll}
\hline Learning Style & Questions \\
\hline Visual & $6,10,12,24,29$ \\
Tactile & $11,14,16,22,25$ \\
Auditory & $1,7,9,17,20$ \\
Group & $3,4,5,21,23$ \\
Kinesthetic & $2,8,15,19,26$ \\
Individual & $13,18,27,28,30$ \\
\hline
\end{tabular}

Major learning style preference: $38-50$

Minor learning style preference: $25-37$

Negligible: 0-24

Another questionnaire survey, composed of 25 questions concentrating on motivation, adapted from Questionnaire on Motivation and Profile of Students by Dryczka (1995), Survey of Motivation by Fujinuma (2005), and Science Motivation Questionnaire by Glynn, Taasoobshirazi, and Brickman (2011) from University of Georgia was to find out about students' motivation in advance of the study. This questionnaire was also translated into Vietnamese to avoid any confusion or misunderstanding when responded to.

The responses in the survey were set in degrees of motivation from choice 0 , least motivation, to choice 4 , most motivated.

Motivation measurement: The responder's motivation was measured according to the score that they obtained from their answers. The maximum score that one may totally get from the survey is 100 and the minimum total score is 0 . The score for each answer is indicated by the number standing for the answer. The measurement was determined as follows:

- Score range: $\leq 30$ points: Low motivation.

- Score range: 31-70: Moderate motivation.

- Score range: 71-100: High motivation.

In order secure the stability and validity of the research study, the 6 classes were divided into 2 groups, the experimental one, including T1, T3, and K6A and the control group, consisting of T2, T4, and K6B. There were a couple of reasons for this division. What first put into consideration was their motivation level. Each pair of classes, T1 and T2,
T3 and T4, K6A and K6B had been determined to be at a similar level of motivation (Fig. 3). Another reason taken into account was their age group. Accordingly, people belonging to different age groups may interact differently (Ebner \& Johnson, 2010).

Stage 2: Discussions with the involved teachers

The assigned teachers were subject to regular discussions with the researcher so that adjustments of teaching strategies were worked out collaboratively.

The study was conducted for 16 weeks since February 2012, a month after the start of the course, to leave enough time to identify the problem and set the research conditions.

The table below illustrates distribution of teachers, in which the teacher in the middle of the row is a Vietnamese teacher, and the other two teachers are foreigners, whose names were abbreviated as initials for confidentiality.

Table 2. Teacher distribution

\begin{tabular}{ll}
\hline Classes & Teachers \\
\hline TU1, TU2 & J, A, S \\
TU3, TU4 & M, D, W \\
K6A, K6B & K, H, L \\
\hline
\end{tabular}

The syllabus was determined in which the teaching material applied was IELTS Express by Richard Hallows, Martin Lisboa and Mark Unwin (2006). This series consists of 2 levels, namely intermediate and upper-intermediate, accompanied by CDs and workbooks. Students learned the textbooks with the teachers in the classroom and workbooks were used for self-study.

The first reason for choosing the book is this material kit, different from some other IELTS training materials, aims at developing all students' 4 skills and provides a large number of opportunities for students' interaction. For example, in terms of reading skill, it gives pre-reading, while-reading, and post-reading activities.

The second worth-studying point in the book is that it is test-oriented although it is applying communicative approach. For instance, Unit 1 in the intermediate-level book provides students with some tips for IELTS speaking parts 1 and 2 . Also, regarding writing skill, Unit 2 gives students hints for discussion before writing and Unit 4 had 2 sample essays.

The final point to note in this series is its lesson topics vary greatly in order that students can improve their vocabulary in a wide range, which is considered an important concern in the IELTS Test.

Stage 3: Collaborative work with the involved teachers

The researcher collaboratively worked with the involved teachers to incorporate revised teaching strategies into their lessons plans and experiment with them in these 6 classrooms. Such elements as teachers, students, and teaching materials which were preserved in the classroom setting to focus on the only variable, revised teaching strategies. Care was taken so as not to lead the teacher to an assumption that, due to the intervention, they have to teach outside of their syllabus.

Stage 4: Regular classroom observation

Classrooms were repeatedly observed, under the revised 
teaching strategies, to measure the enhancement of student interaction, which was recorded by observation checklists adapted from Frohlich and Spada because observation on classes was necessary to limit constraints of reality, supposed to be unclear in advance (Kemmis \& McTaggart, 1998). These potential constraints might have led to bias in the findings.

Stage 5: Feedback collection from the teachers and students

Discussion with teachers to collect their feedback on the efficacy of revised teaching strategies was implemented.

\section{Findings and Data Analyses}

\subsection{Teachers' Feedback}

The teachers, in appointments with the researcher, expressed their feedback on the treatments.

J, A \& S: TU1 has been a great class during the process. At the start, many of them appeared to be slightly or not active. Nonetheless, to the end, they turned to be dynamic. They raised lots of questions and even interrupted the teacher occasionally to make jokes using the target language notes taught. Some of them even volunteered to answer the question or answered without nomination when a classmate who was supposed to speak did not have an answer. Sometimes their utterances were irrelevant to the task, but it was interaction. By contrast, TU2 tended to develop passive rather than active interaction. To be exact, their level of interaction did improve, but they only answered questions when asked. Only once or twice a session did they look active in interaction with the teacher and other students. Commonly some of them seemed to have difficulty understanding the target language. Even when they gained control of the task, they seemed not to get the whole picture.

D, M \& W: There was a clear difference between TU3 and TU4 in terms of interaction. They interacted with the teacher and with each other in different manners and at dissimilar levels. TU3 seemed to be more focused on the task given. The students were keener on interaction with the teacher throughout the process. They even came and talked to the teacher relevantly or irrelevantly during the break time with the hope to achieve a higher proficiency level. During pair work, group work or class work, they discussed together for an answer although some of them had trouble with language and their responses were not always correct. In TU4, meanwhile, the students were probably not eager to exchange their opinions with the teacher and with each other. When they communicated, they meant to make irrelevant jokes, sometimes in Vietnamese. They did develop in interaction over the period of 16 weeks, but they only interacted in the assigned task in classroom. Approximately a fourth raised an idea in English spontaneously, which made up a major difference in the two classes' interaction.

$\mathrm{K}, \mathrm{H}$, \& L: The main difference between K6A and K6B was not in their accomplishment, but in their interaction. Although K6B communicated reluctantly and passively, their responses improved in accuracy and fluency over time like K6A. However, K6A learners interacted with the teachers and within pairs and groups quite dynamically. They frequently posed questions when they had any relevant inquiry. It was not hard to see spontaneous utterances on the target language notes. However, K6B students tended to be more interested in pair and group discussions. They did not interact with the teachers if not asked to.

\subsection{Data Analyses}

\subsubsection{Students' Learning Styles}

Table 3. Findings about Learning Styles

\begin{tabular}{llll}
\hline Percentages of Students by Learning Style & Major Learning Styles & Minor Learning Styles & Negligible Learning Styles \\
\hline Visual & 21.3 & 74 & 4.7 \\
Tactile & 59.3 & 40 & 0.7 \\
Auditory & 80.7 & 19.3 & \\
Kinesthetic & 77.3 & 22.7 & 2.6 \\
Group & 64.7 & 32.7 & 32.7 \\
Individual & 14 & 53.3 & \\
\hline
\end{tabular}

From the data collected, most of the subjects, from slightly under $60 \%$ to marginally over $80 \%$, have tactile, auditory, kinesthetic and group learning styles as their major styles, whereas a minority of students benefit from learning visually and individually.

It can be drawn from the survey that students do not have difficulty learning in class as the methods used in classrooms are not based primarily on individual style. A problem emerging from the figures is that the students with the individual learning style may have trouble in learning writing, which by and large requires writers to work on their own. To deal with the issue, these students are advised by the teacher to discuss in groups for ideas before writing. Alternatively, they can write in groups, in which a writing task is divided into several parts and each of them is in charge of a part.

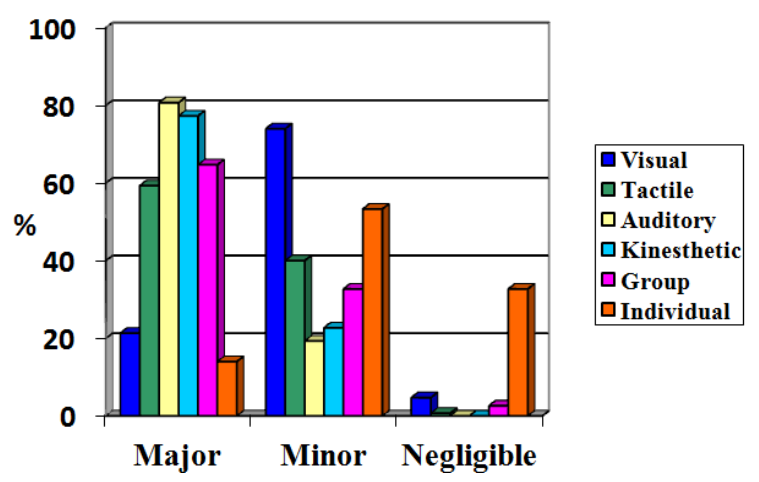

Figure 3. Learning style preferences 
The graph (Figure 3) suggests the researcher and teachers to adapt to the three main learning styles, namely tactile, auditory, and kinesthetic ones.

\subsubsection{Motivation Levels}

Prior to the implementation of the study, a survey on learners' motivation was done. As can be seen from the data collected (Figure 4), the classes of government officials, were, in general, much less motivated than those of young graduates, named K6.

Another point to note is of the four classes of government officials, TU1 and TU2 had higher motivation than TU3 and TU4. To be detailed, TU1 and TU2 in general belonged to the level of high motivation, with $76.04 \%$ and $72.16 \%$ respectively with no student at low motivation level. Meanwhile, the number of lowly-motivated learners in TU3 and TU4 ranged from slightly over $15 \%$ to $20 \%$ and those who were really keen on learning English only accounted for $8 \%$ each.

Although K6A and K6B had the same number of students with both high motivation and moderate motivation, which made up $88 \%$ and $12 \%$ respectively, their mean scores show K6B was, by and large, more lowly-motivated than K6B.

Right after the information about students' motivation collected, the school board had a meeting with the chairman of the project to discuss the problem, which would have led biased findings and all things to be done might have been for nothing. After the meeting, an official announcement was sent to all the course participants and organizations that all of those who were attending the course and then took an overseas degree course would be promoted to a higher position. In addition, they still received the same pay during this English course and their overseas studies. These opinions had been chartered in the project, and announced to all the students orally. However, an official notice may have motivated them to a certain extent. They all appeared satisfied with the announcement

\section{A breakdown of students' motivation by level}

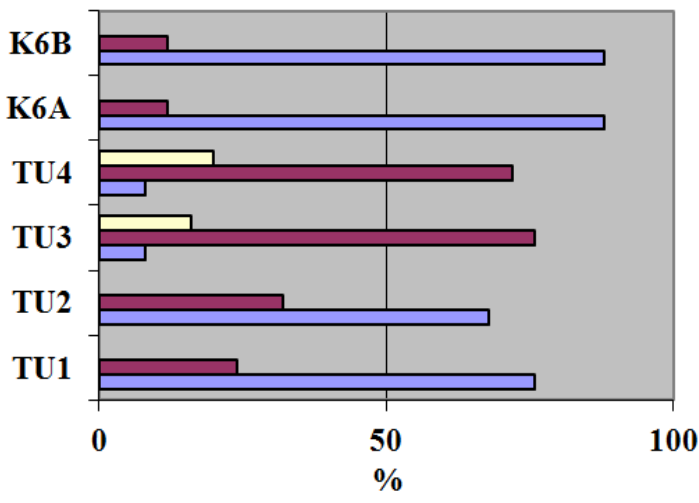

Figure 4. 4 Levels of motivation

Notes:

L: Low motivation

M: Moderate motivation

H: High motivation
Table 4. Average levels of motivation by class

\begin{tabular}{lllllll}
\hline Class & TU1 & TU2 & TU3 & TU4 & K6A & K6B \\
\hline Mean Score & 76.04 & 72.16 & 51.44 & 48.56 & 80.16 & 74.08 \\
Motivation & $\%$ & $\%$ & $\%$ & $\%$ & $\%$ & $\%$ \\
Level & $\mathrm{H}$ & $\mathrm{H}$ & $\mathrm{M}$ & $\mathrm{M}$ & $\mathrm{H}$ & $\mathrm{H}$ \\
\hline
\end{tabular}

\subsubsection{Interaction Levels}

Regarding students' active interaction time (Figure 5), all the three experimental classes, namely TU1, TU3, and K6A, rocketed significantly. However, the controlled group, including TU2, TU4, and K6B, only showed a slight increase in the time interacting dynamically in class. In particular, in the first week of the research there was not much difference in the level of active interaction between the 6 classes. Interestingly, from the eighth week on, the difference took place and began to expand until the end of the treatment. In the last week of the study, there was a difference of around 15 minutes in dynamic communication between the two cohorts, named the trial and the controlled groups.

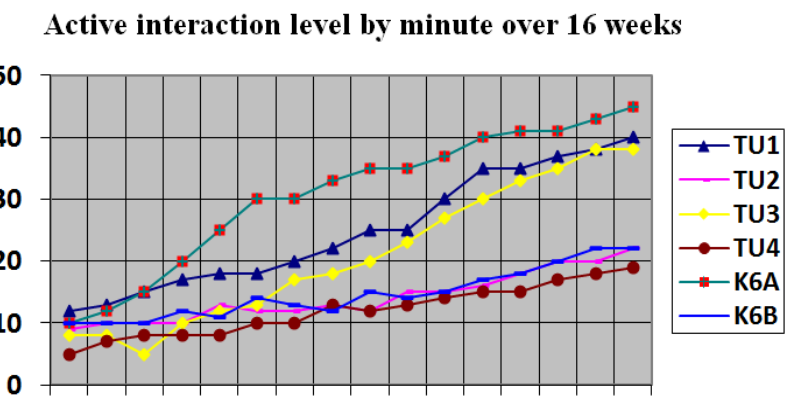

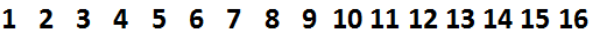

Figure 5. Active interaction levels

Table 5. Passive interaction levels

\begin{tabular}{lllllll}
\hline Week & TU1 & TU2 & TU3 & TU4 & K6A & K6B \\
\hline 1 & 25 & 20 & 25 & 22 & 25 & 22 \\
2 & 24 & 22 & 25 & 20 & 25 & 25 \\
3 & 25 & 25 & 28 & 23 & 24 & 25 \\
4 & 28 & 26 & 30 & 23 & 27 & 25 \\
5 & 29 & 28 & 30 & 25 & 27 & 25 \\
6 & 30 & 29 & 29 & 27 & 28 & 30 \\
7 & 30 & 29 & 30 & 28 & 30 & 32 \\
8 & 29 & 27 & 28 & 30 & 29 & 31 \\
9 & 28 & 28 & 29 & 31 & 30 & 29 \\
10 & 30 & 27 & 27 & 30 & 31 & 33 \\
11 & 28 & 29 & 26 & 32 & 29 & 31 \\
12 & 22 & 30 & 25 & 31 & 27 & 29 \\
13 & 25 & 29 & 23 & 32 & 26 & 30 \\
14 & 20 & 28 & 21 & 30 & 27 & 31 \\
15 & 22 & 30 & 19 & 29 & 25 & 30 \\
16 & 20 & 31 & 20 & 30 & 25 & 29 \\
\hline
\end{tabular}

In terms of passive interaction, the three treated classes demonstrated an increase of 5 minutes each in the first 7 weeks and then declined steadily until the end of the study. This might reflect a fact that students transferred this amount of time from passive interaction to active interaction (Table 5 $\&$ Figure 6). Meanwhile, the 3 controlled classes experienced a dissimilar trend, in which the students slightly developed their interaction in the first 7 weeks and then this figure 
remained constant throughout the rest of time. This minor improvement in interaction time, compared to the three aforementioned classes, might be because their proficiency grew during the implementation.

Passive interaction level by minute over 16 weeks Unit: minutes

It is also vital to figure out the rise in the total amount of interaction time in class (Figure 6). Although the 3 controlled classes did not interacted as much more as the 3 treated classes, they underwent a steady growth in the total amount of interaction time. The group that obtained a higher improvement in interaction, as expected, was the trial one, varying from 22 to 35 minutes. By contrasting the two groups, on average, the rate of interaction of the controlled group was roughly 12 minutes higher than that of the experimental group.

Total amounts of interaction time every session by class Unit: minutes

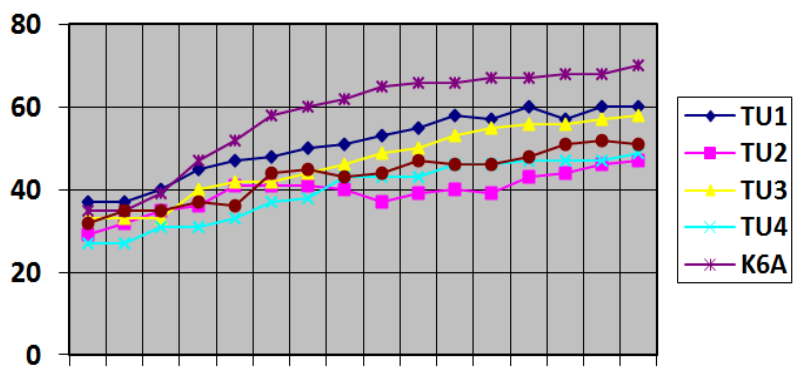

$\begin{array}{lllllllllll}1 & 2 & 3 & 4 & 5 & 6 & 7 & 8 & 9 & 10111213141516\end{array}$

Figure 6. Total interaction time

\section{Conclusion}

\subsection{Overall Assessments}

Throughout the content of this paper, teachers as well as students realize more about the importance of understanding learning styles to enhance students' interaction in classroom. Thanks to the literature review and the findings, adjusting teaching strategies based on students' learning styles can help students at IEC to interact more dynamically in classroom. The thesis also found that the learners' interaction depends considerably on whether teaching styles match students' learning styles and how motivated they are.

\subsubsection{Strengths}

The researcher's commitments with the subjects and involved teachers partly contributed to the success of the study. Firstly, when designing the study, the researcher took advantage of the time he had been with the students to trial the assumption beforehand. This correct diagnosis paved the way to smooth conduction. Responsible for their studies for some weeks ahead of the implementation of the research, he realized that the students were quite passive in classroom activities. Secondly, the relationships between the teachers and the research conductor and the students were strong enough for them to support the thesis with enthusiasm. That means, when the questionnaire was delivered to them, they were willing to give their answers. Invaluable advice and assistance from his coworkers helped the researcher achieved successfully. These factors contributed a great deal of reliability of the research findings as well as the verification of the perspective.

\subsubsection{Limitations}

It is not sure that the system also works in other cases since the scope of this study was quite small and limited, with only 150 students at the same level participating in the survey for the purpose of 6.0 IELTS.

However hard the researcher tried, people in different cultures may prefer to learn differently (Berry, 1966). Hopefully, in the near future, other research papers on this topic title in general and relevant fields of interest will need to be conducted to confirm the theories. The researcher also hopes that the recommendations in this thesis partly help improve English teaching and studying not only at IEC but also at many other local language centers.

The research did not figure out the clear correlation between students' motivation levels and classroom interaction as well as the correlation between the use of the native language in foreign language classroom and the growth of interaction amongst students and between the teacher and students. Although these are not the aims of the study, the findings seem to reflect a fact that these correlations were not accidental. Successive studies should illuminate these points.

\subsubsection{Recommendations from the Research}

The research study did prove a close connection between interaction and teaching styles. Accordingly, if the applied teaching style does not match students' learning styles preferences, students may interact slightly. To a considerable extent, interaction stems from the teacher's application of an appropriate teaching style which his students prefer. The understanding of students' learning styles can interest students in learning and involve them in class activities. Teachers also have to identify students' motivation levels because the aforementioned concept is not the only factor for interaction development in classroom. In order to ensure that interaction takes place, the teacher also needs to consider the amount of input based on the students' general level. If the input exceeds " $i+1$ " (Krashen, 1982), learners may suffer language barriers; as a result, they find interaction a kind of challenge.

\section{References}

[1] Berry, J.W. (1966). Temne and Eskimo perceptual skills International Journal of Psychology, 1, 207-199.

[2] Burns, A., \& Joyce, H. (1997), Focus on Speaking, Sydney: National Center for English Language Teaching and Research.

[3] Dryczka, J. (1995), Promote Language Learning among the Whole Academic Community, University of Warmi SkoMazurski: 10-957. Olsztyn Oczapowskiego, Poland. 
[4] Ebner, N. C. \& Johnson, M. K.(2010), Age-group differences in interference from young and older emotional faces, Cognition \& Emotion, Psychology Press. London: UK, 24: 7, $1095-1116$.

[5] Frohlich \& Spanda (1995), Classroom Observation Checklist for Vietnamese English Classes, Victoria University Press.

[6] Fujinuma, A. (2005), The Key Management Strategy in 2010, Nomura Research Institute, Ltd., Japan.

[7] Gardner, H. (1993), Frames of Mind: The Theory of Multiple Intelligences, New York: Perseus Books Group.

[8] Glynn, S. M., Taasoobshirazi, G. \& Brickman, P. (2007). Nonscience majors learning science: A theoretical model of motivation. Journal of Research in Science Teaching, 44, 1088-1107.

[9] Good, T., \& Brophy, J. (1987), Teacher Expectations as SelfFulfilling Prophecies. In Clarizio Harvey F. Rober C. Craig, \& William A. Mehrens (Eds.), Contemporary Issues in Educational Psychology, New York: Rahdom House.

[10] Hallows, R., Lisboa, M., \& Unwin, M. (2006), IELTS Express, Intermediate and Upper-inter mediate, London: Thomson ELT.

[11] Harker, J. O. (1988), Individual and Team Approaches: An Introduction. In Green, Judith L., \& Hyman, R., \& Rosoff, B. (1987), Matching Learning and Teaching Styles: The Jug and What's in It. In Clarizio, Harvey F. Robert C. Craig, \&
William A. Mehrens (Eds.), Contemporary Issues in Educational Psychology, New York: Random House.

[12] Honey, P. \& Mumford, A. (1982) Manual of Learning Styles, London: P Honey.

[13] James, W. B., \& Gardner, D. L. (1995), Learning Styles: Implications for Distance Learning, New Directions for Adult and Continuing Education, 67, 19-32.

[14] Kelen, C. (2000), Perpetual Motion: Keeping the Language Classroom Moving, The Internet TESL Journal, Vol. VI, No. 1.

[15] Kemmis, S., \& McTaggart, R. (1988a). The action research planner (3rd ed.). Geelong, Australia: Deakin University Press.

[16] Kolb, D. (1984), Experiential Learning experience as a Source of Learning and Development, NJ: Prentice-Hall.

[17] Krashen, S. (1982), Principles and Practice in Second Language Acquisition, London: Pergamon.

[18] Reid, J. (1987), The Learning Style Preferences of ESL Students, TESOL Quarterly, 21/1, 87-111.

[19] Willing, K. (1988), Learning Styles in Adult Migrant Education, Adelaide: National Curriculum Resource Center.

[20] Worthley, K. M. (1987), Learning Styles Factors of Field Dependence/ Independence and Problem-Solving Strategies of Hmong Refugee Students. Unpublished Master Thesis. University of Wisconsin, Stout, WI. 